\title{
Acculturation Strategies among Chinese Immigrants in the American Labor Market - A Survey on Immigrants from Guantou Town, Fujian Province
}

\author{
Xingying Zhou \\ Guangdong University of Foreign Studies \\ Liangmei Yu \\ Fujian Agricultural and Forestry University
}

The current exploratory study takes the Guantou town immigrants as its target group to explore how they acculturate in the American labor market. The immigrants' major acculturation strategies have been identified based on Berry's bidimensional model of acculturation. Results reveal that integration and separation are the immigrants' major preference of acculturation strategies. How the variables within each one of the two sets (demographic and intercultural contact) affect immigrants' preference for different strategies has been tested. Descriptive analysis and correlation analysis show that some general relationships could be predicted in terms of immigrants' demographic features and the intercultural contact factors. The authors have interviewed 18 participants through online $Q Q$ chatting system about their conceptions of the American Dream. Interview results indicate immigrants' acculturation difficulties, which reflect their acculturation patterns or acculturation dilemma where psychologically the general Guantou town immigrants have unconscious tendency to the integration strategy, while in practice they choose to separate for being conditioned by those acculturation difficulties.

\section{INTRODUCTION}

"Global village" is no longer a new notion. Nowadays, it becomes more and more convenient for people to move from one culture to another. The United States is known to be a nation of immigrants. Chinese immigration in the United States has witnessed 150 years of history (Asia Society, 2010). Through the long history of immigration, the changing urban communities in America have become gateways for new immigration (Liang, 2010). The reasons why Chinese immigrants leave their home country vary (Tian, 1999). Nonetheless, many immigrants leave for the United States, apparently mainly for the purpose of working, including those unauthorized labor immigrants and those with various kinds of employment-based visas and with the various preference categories for family reunification visas (Sorensen, Bean, Ku, \& Zimmerman, 1992). 
Though there is an increase in Chinese immigration into the United States, in the field of psychological acculturation, most of the target groups of the previous studies are Mexican Americans, Hispanics in the U.S., African Americans, and multiple groups (see Matsudaira, 2006 for a recent literature review). Even though some psychological acculturation studies concern Asian groups, few of them focus on the East Asian (e.g. the Chinese immigrants) and other Asian ethnic groups in the United States (Barry, 2001). Among the acculturation studies concerning the Asian Americans, the Suinn-lew Asian Self-Identity Acculturation scale (SLASIA) (Suinn, Rickard-Figueroa, Lew, \& Vigil, 1987) is the most widely used measure. However, it has been criticized, for it does not adequately recognize that individuals may display varying patterns of acculturation in different situations (Mendoza, 1984). Though Berry's bidimensional model of acculturation is conceptually rich, his measures seem to have limited utility with the Chinese immigrants. Based on Berry's and Sunni's studies, Barry (2001) has proposed the East Asian Acculturation Measure (EAAM) to examine the acculturation patterns of East Asian immigrants for clinicians' and researches' working references. In addition, Ku and Aung (2007) have found that a majority of the acculturation studies utilize quantitative research methods, and thus they have proposed a combination of qualitative and quantitative methods. Consequently, the uniqueness of the young Guantou town immigrants has direct implications both for future research and immigration consulting services for the general Chinese immigrants.

The present study takes a survey of the young immigrants from Guantou town (hereinafter referred to as Guantou town immigrants) to explore how they acculturate in the American labor market. Based on a quantitative survey questionnaire developed mainly with reference to Berry and his colleges' (2006) ICSEY project, the study evaluates the major acculturation strategies among the Guantou town immigrants. Furthermore, the study investigates whether and how the variables concerned affect the Guantou town immigrants' preference for the acculturation strategies. In particular, two sets of variables have been taken into account: demographic (age, gender, length of stay in the U.S., education background) and intercultural contact (ethnic identity, national language proficiency, in-group and out-group social interaction, perceived discrimination, self-esteem, sociocultural adaptation). Finally, some basic information gathered before this research inspires the study to reveal the acculturation difficulties and the distinctive acculturation patterns of the Guantou town immigrants through online interview, which evaluates how their conceptions of the American Dream influence their acculturation process, especially, their preference for the acculturation strategies.

\section{Background of the Guantou Town Immigrants}

Guantou town lies in the south of Lianjiang County in Fuzhou, Fujian Province. With a population about 60,000, Guantou town is a famous overseas Chinese hometown. Driven by the American Dream and the imagined better life in the United States, many a Guantou town resident migrates to the United States for family reunion, making a living, or, for few, furthering their study. Whatever the reasons, they finally all end up working in the United States. Usually, young immigrants, ages 3 to 20, go to the United States with their father and/or mother. An important condition for them to migrate is that one of the young immigrants' parents applies for their immigration to the United States. For the purpose of the present study, the term immigrant is utilized exclusively to refer to individuals who enjoy legal status in the United States.

Most of these young immigrants hold a low level of education (i.e., with or without high school diploma) before going abroad. As is known, work is an indispensible part of the adolescent experience in the United States. The early working experience of the youth could win 
them the edge to be more competitive in their future employment and earnings (Ruhm, 1997). However, few young people in China work during or before their high school years. This reflects one part of the cultural difference-that the Chinese and Americans hold different values concerning work and money. Immigrant youth with or without high school diplomas, or with little early working experience at home, may be cornered to the edge of economic disadvantage when they migrate to a new culture.

As a matter of fact, they are undergoing major psychological and sociocultural changes, especially when they are trying to adapt to a new culture. The process of cultural change and adjustment is defined as "acculturation." During the acculturation process, immigrants often experience acculturation stress which leads to anxiety, depression, and feelings of marginality, alienation, and identity crisis.

\section{Literature on Acculturation and Acculturation Studies}

Originated in anthropology, acculturation has become one of the major areas of investigation in cross-cultural psychology. In psychology, acculturation is the process of cultural and psychological changes with intercultural contact (Berry, Phinney, Sam, \& Vedder, 2006). Making the distinction between the cultural and psychological levels of acculturation is crucial to identify individual differences in acculturation (Berry, 2003). Psychological acculturation refers to changes in behaviors, attitudes, values, and identities of individuals (Berry, 1980). For the purpose of this study, the use of the term acculturation refers to psychological acculturation.

There are three levels of acculturation studies: group, contextual and individual. The group level focuses on the changes for both cultures in the field of political, economic, demographic, and cultural changes. In general, anthropologists (e.g., Redfield, Linton, \& Herskovits, 1936) and sociologists (e.g., Gordon, 1964) tend to focus on the group level adaptation of the immigrants and foreign sojourners. Young Yun Kim's (2001) integrative theory of cross-cultural communication takes the contextual dynamics of cultural and psychological adaptation into consideration. Thus, the contextual level focuses on the changes both for the individual and the host culture, resulting from the interplay between the two parties.

The individual level deals with the changes an individual experiences due to being in contact with another culture. In cross-cultural psychology, focus of acculturation research has expanded to include changes on the individual level, which is usually referred to as psychological acculturation (Graves, 1967). More recent understanding of acculturation suggests that psychological acculturation is bidimensional or multidimensional. Berry (1997) has developed the most widely researched bilinear or bidimensional model of acculturation. Berry (1980) has proposed the existence of acculturation strategies or acculturation attitudes. In Berry's (1997) conceptual matrix of acculturation attitudes, two independent attitudinal dimensions have been proposed, that is, the degree to which people wish to maintain their cultural identity and the degree to which people seek involvement with the larger society. When these two attitudinal dimensions are crossed, an acculturation space is created with four sectors (assimilation, separation, integration, and marginalization) within which individuals may express how they are seeking to acculturate. The assimilation strategy is characterized by individuals who do not wish to maintain their ethnic identity and seek a high level of integration in the host culture. Separation is identified by the pattern of acculturation in which individuals retain and have a strong orientation to their ethnic culture while rejecting and avoiding interaction with the host culture. Integration strategy is characterized by individuals who embrace and value both their ethnic culture as well as the host culture. Last, marginalization entails those individuals who are 
both excluded (either voluntarily or by force) from their ethnic culture as well as from the host culture.

To test the four strategies of acculturation, Berry's bidimensional model of acculturation is adopted as the dominant theoretical framework to address the individual level of acculturation of the Guantou town immigrants in the American labor market.

\section{Intercultural Contact and the American Dream}

Intercultural contact, as a worldwide experience, is the core concept of the acculturation process. Immigrants have constituted an important group in the American society, and intercultural contact is an essential part of their life in the host culture. Ward, Bochner, and Furnham (2001) have suggested that social identification, culture learning, and stress and coping frameworks represent comprehensive conceptual bases for the study of intercultural contact and change. Social identification framework involving the changes in ethnic identity is the way people view themselves and others. The cultural learning framework stresses the significance of social skills and social interactions. Stress and coping framework emphasizes the affective component of intercultural contact and change. Immigrants evaluate themselves in the new culture and their intercultural experiences. In this survey, ethnic identity (F1), national language proficiency (F2), in-group and out group social interaction (F3), perceived discrimination (F4), self-esteem (F5), and sociocultural adaptation (F6) are regarded as the central variables in intercultural contact that affect the Guantou town immigrants' acculturation in the American labor market.

The concept of the American Dream has gone through transformations throughout history. People may hold different conceptions of it today. However, its central concept has mostly remained intact. Such key concepts as personal and economic security, freedom of expression, and freedom to live the way one chooses form the underlying basis of the most definitions. How the idea of the American Dream affects the immigrants' acculturation is a relationship which merits attention. It is an important question to ask today because according to Cullen (2003), within notions of the American Dream is the assumption that anyone who pursues their vision of the Dream can indeed achieve it provided their level of personal agency and/or commitment is sufficient. This reflects the American value of individualism, which provides justification for why some immigrants experience acculturative stress in the new culture. Therefore, inquiring about the immigrants' conceptions of the American Dream is meaningful in revealing the immigrants' acculturation difficulties and distinctive acculturation patterns, and the reasons for their preference of acculturation strategies.

\section{THE RESEARCH METHODS}

In pursuit of how the Guantou town immigrants acculturate in the American labor market, the present survey adopted the combined research methods of quantitative and qualitative study. Questionnaire and interview were designed to obtain data.

\section{Participants and Procedures}

Eighty-four Guantou town immigrants currently working in the United States were included in the present study. All participants filled out the questionnaires, and eighteen of them were interviewed online. The target participants were reached through the following approaches. 
First, while attending the middle school in Guantou town, the author made friends from that area who are now working in the United States. Questionnaires were distributed via e-mail to these friends for distribution. Second, one of the author's friends was an immigration counselor and translator in Guantou town who had archives of his clients and helped the author reach some immigrants in the United States. Finally, a snowball technique was employed. Some immigrants' contact information was provided by friends' friends. Moreover, by joining a Guantou town immigration QQ group, the second author reached many immigrants.

The age of the participants ranged from eighteen to twenty-nine $(\mathrm{M}=24.52, \mathrm{SD}=2.17)$. Fortyeight $(57.14 \%)$ of them were males and thirty-six $(42.86 \%)$ of them were females. The participants' length of stay in the United States stretched from six months to ten years, and about $33.33 \%$ of them had stayed in America for four to six years. Most of their education backgrounds were low, for $65.47 \%$ of the participants only held senior high school or junior high school diplomas, and only $22.62 \%$ of them had furthered their study to the junior college or a higher level. Forty of them revealed their QQ number in the questionnaires. Though fifty-six participants revealed their occupations in the questionnaires, $42.86 \%$ of the occupations provided such as service sector, catering, and working were too general.

\section{Instruments}

The instruments used in the study were questionnaire and interview. The questionnaire was mainly used to investigate the immigrants' major preference of acculturation strategies, and the questions involved in the interview assisted in exploring the reasons for their acculturation tendencies. Details concerning how these instruments were developed and the contents and structures of these instruments will be elaborated on in the following sections.

\section{Development and Analysis of the Questionnaire for the Present Study}

The development of the questionnaire for the present research mainly referred to the questionnaire used in the project of International Comparative Study of Ethnocultural Youth (the ICSEY project) (Berry et al., 2006). The ICSEY project was developed and carried out by a group of psychologists from 13 countries. This project began as a sequel to studies then being carried out in Canada, Norway, and the United States. The measures used in the project of ICSEY were compiled by an international group of researchers. The current questionnaire consisted of 56 questions that were divided into three parts: the demographic section, the Acculturation Scale, the intercultural contact factors. The scale assessed four acculturation strategies (assimilation, integration, separation and marginalization) in each of five domains: marriage, cultural traditions, language, socialization and friends. Examples of the item examining each of the subscale were: "I feel more comfortable socializing with Americans than I do with Chinese" (assimilation); "I prefer to have only Chinese friends" (separation); "I feel that I should maintain my own cultural traditions but also adapt to those of Americans" (integration); "It is not important to me to be fluent either in Chinese or English" (marginalization). With the exception of demographic items, all the items reported in the questionnaire were answered on a 5 -point Likert scale ranging from 1 (strongly agree) to 5 (strongly disagree). The items were randomly ordered. In order to minimize language difficulties and increase response rates, the English version of the questionnaire was developed first and then translated into Chinese.

Since the present study referred to the scales used in ICSEY project, Barry's East Asian Acculturation Measure (EAAM) (Barry, 2001), and Ward and Kennedy's Socio-Cultural Adaptation Scale (SCAS) (Ward \& Kennedy, 1999), it was necessary to show the reliability and 
validity of the modified part of the questionnaire. The ICSEY study had worked out the mean Cronbach alpha scores of the scales. All the questionnaire items were processed for reliability analysis and the results concerned had been summarized in Berry and his colleges' paper (2006).

In ICSEY study, most scales enjoyed good reliability. Though the subscales for acculturation attitudes had slightly problematic reliabilities, these subscales had shown great reliability when they were modified and applied in other research (e.g., EAAM). In Barry's East Asian Acculturation Measure, satisfactory reliability was reported for the four acculturation scales. Its reliability was calculated using Cronbach's alpha, which led to coefficients of $0.77,0.76,0.74$, and 0.85 for assimilation, separation, integration, and marginalization scales respectively. This internal reliability appeared to provide content validation for the EAAM. In addition, previous research using the Socio-Cultural Adaptation Scale (SCAS) also showed satisfactory reliability, such as Chinese students in Singapore and Japanese students in New Zealand, reporting internal reliability alpha coefficient of 0.85 and 0.88 , respectively (Ward \& Kennedy, 1999). Statistically, the items in ICSEY study, Barry's EAAM and Ward and Kennedy's SCAS had a good internal consistency and they were reliable to be modified for the present research purposes.

Factor analysis was generally adopted in the testing of construct validity. The modified twenty-item acculturation attitudes scale was not processed in factor analysis for its categorical nature. Fan (2004) also modified the questionnaire of the ICSEY project in his research of the acculturation strategies among Chinese overseas students in America. Six similar items of the present study concerning perceived discrimination and in-group and out group social interaction were included in Fan's questionnaire. Through factor analysis of his questionnaire, Fan (2004) concluded that his instrument was valid. The researchers of ICSEY study had examined whether the scales measured the same psychological constructs in all cultural groups in all countries using a procedure described by Van de Vijver and Leung (1997) as structural equivalence. The ICSEY collaborators had found very strong support for the structural equivalence of the measures. In ICSEY project, high agreement indexes in all comparisons were found for assimilation, separation, marginalization, ethnic identity, and proficiency in national language. The construct validity of the Socio-Cultural Adaptation Scale (SCAS) had been supported by significant correlations (range $=.20-.62, \mathrm{M}=.38$ ) between sociocultural adaptation and psychological adjustment as measured by the Zung Self-rating Depression Scale (Ward \& Kennedy, 1999).

\section{Contents and Structure of the Interview}

Informal interviews were conducted via online QQ chatting system after the questionnaire survey. Fourteen open-ended questions were designed beforehand to elicit participants' opinions. The general questions were designed to investigate Guantou town immigrants' understanding of America, reasons for going abroad, integration barriers, and expectations. All interviews were conducted in Chinese. The interview transcripts were saved in the QQ chatting system and copied for further analysis. The names of the research participants were made up according to their QQ nicknames or their family names for the sake of participants' privacy. Each set of transcript was analyzed to discern thematic structures. As Owen (1984) had stated, "a theme usually could be identified on the condition that any of these criteria emerge: recurrence, repetition, and forcefulness." 


\section{RESULTS}

The results from questionnaires processing and interviews categorizing were presented, respectively. Raw data from the questionnaires were computed by SPSS 16.0 statistical package and data from interviews was categorized according to the thematic structures.

\section{Immigrants' Preference of Acculturation Strategies}

The analyses of the preference of the acculturation strategies of the eighty-four participants were based on the categorization where participants were sorted into four acculturation strategies. There were twenty items in the second part of the questionnaire which were sorted into four variables with reference to the four acculturation strategies. Mean scores were calculated to compute the overall score for each acculturation strategy. The mean scores were 3.78, 2.12, 3.02 and 3.87 for assimilation, integration, separation and marginalization respectively. As the fivepoint Likert scale ranges from 1 "strongly agree" to 5 "strongly disagree," the lower the score was, the stronger the preference was. Judging from the mean scores of the four acculturation strategies, the participants' general choices became apparent: integration and separation were the major acculturation strategies among Guantou town immigrants. Assimilation and marginalization were the least preferred ones.

\section{Demographic Features and the Immigrants' Preference of Acculturation Strategies}

Table 1 and Table 2 show that some general relationships can be predicted in terms of immigrants' age, gender and length of stay in the United States. Participants of the youngest age range integrate into the American culture well, while the middle age range shows participants' certain confusion in their attitudes towards the new culture, and the last age range is more rational and flexible with integration as their dominant acculturation strategy and the other strategies as the complementary ones. Females show more diverse preference comparing with the male group, while males are more devoted to the integration strategy. Therefore, male immigrants tend to balance the two cultures better than the female ones.

TABLE 1

PARTICIPANTS' PREFERENCE IN TERMS OF AGE AND GENDER

\begin{tabular}{|c|c|c|c|c|c|c|c|c|c|c|}
\hline \multirow{2}{*}{ Strategy } & \multicolumn{2}{|c|}{$18-21$} & \multicolumn{2}{c|}{$22-25$} & \multicolumn{2}{c|}{$26-29$} & \multicolumn{2}{c|}{ Male } & \multicolumn{2}{c|}{ Female } \\
\cline { 2 - 11 } & NO. & $(\%)$ & NO. & $(\%)$ & NO. & $(\%)$ & NO. & $(\%)$ & NO. & $(\%)$ \\
\hline Assimilation & 1 & 25.00 & 1 & 1.82 & 2 & 8.00 & 2 & 4.17 & 2 & 5.56 \\
Integration & 4 & 100.00 & 50 & 90.91 & 25 & 100.00 & 48 & 100.00 & 31 & 86.11 \\
Separation & 3 & 75.00 & 16 & 29.09 & 10 & 40.00 & 19 & 39.58 & 10 & 27.78 \\
Marginalization & 0 & 0.00 & 3 & 5.46 & 3 & 12.00 & 3 & 6.25 & 3 & 8.33 \\
None & 0 & 0.00 & 3 & 5.46 & 0 & 0.00 & 0 & 0.00 & 3 & 8.33 \\
\hline
\end{tabular}

The fifth year sojourning in the United States is a transitional year for the immigrants and usually the longer they stay, the more sophisticated they become in dealing with the two cultures. No inevitable relationship can be predicted between participants' education background and their preference for each acculturation strategy. 
TABLE 2

PARTICIPANTS' PREFERENCE IN TERMS OF LENGTH OF STAY

\begin{tabular}{|c|c|c|c|c|c|c|c|c|c|c|}
\hline \multirow{2}{*}{ Strategy } & \multicolumn{2}{|c|}{$(0-2]$} & \multicolumn{2}{c|}{$(2-4]$} & \multicolumn{2}{c|}{$(4-6]$} & \multicolumn{2}{c|}{$(6-8]$} & \multicolumn{2}{c|}{$(8-10)$} \\
\cline { 2 - 10 } & NO. & $(\%)$ & NO. & $(\%)$ & NO. & $(\%)$ & NO. & $(\%)$ & NO. & $(\%)$ \\
\hline Assimilation & 0 & 0.00 & 2 & 10.53 & 1 & 3.57 & 0 & 0.00 & 1 & 10.00 \\
Integration & 12 & 92.31 & 18 & 94.74 & 26 & 92.86 & 13 & 92.86 & 10 & 100.00 \\
Separation & 5 & 38.46 & 5 & 26.32 & 11 & 39.29 & 4 & 28.57 & 4 & 40.00 \\
Marginalization & 1 & 7.69 & 0 & 0.00 & 2 & 7.14 & 1 & 7.14 & 2 & 20.00 \\
None & 0 & 0.00 & 1 & 5.26 & 1 & 3.57 & 1 & 7.14 & 0 & 00.00 \\
\hline
\end{tabular}

\section{Correlation Analysis for the Strategies and the Intercultural Contact Factors}

The correlation analysis was processed for the acculturation strategies, and the six factors explored whether there was any statistically significant relationship between them. The current study summarized the correlations for each strategy and the six intercultural contact factors in Table 3.

TABLE 3

CORRELAYIONS FOR EACH STRATEGY AND SIX FACTORS

\begin{tabular}{|c|c|c|c|c|c|c|c|}
\hline \multicolumn{2}{|c|}{ Strategy } & F1 & F2 & F3 & F4 & F5 & F6 \\
\hline Assimilation & Pearson & $\mathbf{- . 2 3 7}$ & .095 & -.019 & $\mathbf{. 2 6 5}$ & .181 & .188 \\
& Correlation & $\mathbf{. 0 3 0}$ & .392 & .862 & $\mathbf{. 0 1 5}$ & .100 & .087 \\
& Sig. (2-tailed) & & & & & & \\
\hline Integration & Pearson & .022 & .096 & .088 & -.134 & .147 & .002 \\
& Correlation & .846 & .386 & .425 & .225 & .182 & .983 \\
& Sig. (2-tailed) & & & & & & \\
\hline Separation & Pearson & -.068 & .120 & $\mathbf{- . 2 6 6 *}$ & $\mathbf{. 7 4 3 * *}$ & $\mathbf{- . 2 5 4 *}$ & $\mathbf{. 3 7 7 * *}$ \\
& Correlation & .542 & .278 & $\mathbf{. 0 1 4}$ & $\mathbf{. 0 0 0}$ & $\mathbf{. 0 2 0}$ & $\mathbf{. 0 0 0}$ \\
& Sig. (2-tailed) & & & & & & \\
\hline Marginalization & Pearson & $\mathbf{- . 5 0 2 * *}$ & $\mathbf{. 2 9 4} * *$ & -.081 & $\mathbf{. 2 4 2 *}$ & $\mathbf{- . 2 7 8 *}$ & -.094 \\
& Correlation & $\mathbf{. 0 0 0}$ & $\mathbf{. 0 0 7}$ & .466 & $\mathbf{. 0 2 6}$ & $\mathbf{. 0 1 0}$ & .396 \\
& Sig. (2-tailed) & & & & & & \\
\hline
\end{tabular}

The absolute values ranging from 0.400 to 0.700 suggest significant correlations, those higher than 0.700 are considered to be highly significant, and coefficient from 0.200 to 0.400 shows low correlation with those lower than 0.200 , indicating no correlation. The one asterisk and two asterisks on the up right corner of the coefficient suggest that the significance level reaches 0.05 and 0.01 respectively. Statistics reveal that all the intercultural contact factors do have certain influence on the Guantou town immigrants' preference of acculturation strategies. However, most of the correlations are low. Therefore, the intercultural contact factors have minor impact on the immigrants' choices of the different acculturation strategies.

\section{Results from the Interviews}

This section turns to the qualitative analysis of the data collected from eighteen separate interviews which were carried out with eighteen randomly selected participants who revealed their QQ number in the questionnaires. 


\section{Understanding of the American Dream}

No participant has a clear and comprehensive idea of America before leaving China. Eleven participants have heard of the concept of the American Dream, mainly from mass media. When asked what the American Dream means to them, most responses are far from positive. As Zhong says, "They are broken dreams." Zhang adds sadly, "I think it is a nightmare. People from our town are working for 12 or 13 hours a day. The work is really tiresome." Only Wu says positively, "You can be somebody if you work hard in America and that is what American Dream means."

\section{Reasons for Going Abroad}

Eleven participants' reason for immigration is to make money. Six participants have no other choice but to go with the flow of immigration or have reunion with their parents in America. One participant skips the question. Fifteen participants believe that working in America means a higher salary, more employment opportunities, equal chance, and equal payment. As Wei suggests, "We are given equal chances here, while in China we need to have some kind of human relationship or Guanxi." Be it immigrants' initial intention to leave for America, making money ends up topping on the list of the reasons for them to stay. Making more money entails the ability to purchase and save. The ability to save money makes immigrants' planning for their future possible. Fourteen immigrants hope to earn and save enough money either for future investment or enjoying their life after retirement. As Hou says, "I dream to have a restaurant of my own. After earning enough money, I will do things that I always want to do.”

\section{Communication with the Americans}

Thirteen participants answer for sure that English is the greatest barrier for them to integrate into the American life. For working reasons, all the participants have tried to improve their English either through middle high school study in China, training in some English training center, classes organized by the churches, or self study. However, they do not find themselves belonging to the mainstream culture. All their contacts with the new culture and the people around are driven by their surviving purposes. As Su explains, "We seldom have any contact with the Americans except for those (American) customers. Our life circle is so small that we have no so-called American friends." Nonetheless, eleven participants have positive impressions of the Americans, especially the white Americans, and twelve participants desire to become American citizens for its advantages. As Wu, the American citizen now, says, "Americans enjoy lots of national treatments. I'm not really like to but I have to be an American citizen to move around smoothly in this society. Actually, I may not sit for the exam to become an American citizen if not for necessity."

\section{Relatives and Friends Network}

Most participants have relatives in America who become hard working, mean, or even selfish. These changes could be generalized by a single adjective, independent from the Americans' point of view. However, participants perceive this word as "utilitarian" or "realistic," which conveys a derogatory meaning in Chinese. As Lin states, "They become realistic. It is beyond people's control. Since people come here to earn money, it is natural for them to become utilitarian." It is similar to what Hou says, "Whoever comes to America will become realistic. It is mostly on the level of money. Earning money is full of hardship in America and they value 
their money very much." Apparently, immigrants are unconsciously influenced by some of the American values in their acculturation.

\section{Life and Focus in the U.S.}

The recurrent theme of "making money" points to the solitary and mechanic nature of the life the participants undergo in America. Confined by the nature of their work, most participants' social circles are small. As Huang elaborates, "For some immigrants, the longer they stay, the more silly they become. Some stay in the same place for several years and their social network are always the same. I mean they disconnect with the society." When asked whether immigrants have focused on integrating into the American mainstream culture, most immigrants indicate that they have been trying to integrate for survival. As Chen says, "Trying to integrate does not mean psychological acceptance of the new culture; it's more like what we say, surviving the fittest." Su further explains, "In reality, it's kind of difficult for us to integrate though we may try to, for some of us are hindered by their poor English and long working hours." Obviously, immigrants' unconscious tendency to integration is conditioned by their integration abilities.

\section{DISCUSSION}

Participants have a strong preference for integration, and separation is usually supplementary to the former. These two scales are interrelated and not mutually independent, for participants with the tendency to maintain the Chinese culture and involve with the American culture are showing more inclination to retain the Chinese culture. It is virtually a degree of preference. Immigrants' separation strategy is within the integration strategy. Rudmin (2003) has suggested that the most persistent criticism of the acculturation strategies scales is that the four subscales are not substantially independent. Both the quantitative and qualitative results of the current study test Berry's four acculturation strategies and find out the same problem as Rudmin suggests.

As one of the demographic features, age is proved to be the predictor of the four acculturation strategies. With little social experiences, the youngest participants (18-21) are usually ready to integrate into the new culture. However, they are multifaceted. Though they show higher frequency in assimilating into the mainstream culture, they in effect feel more close to the ethnic culture for holding low English proficiency levels. That is why over $70 \%$ of them show preference for separation as well as integration. Participants of the oldest age range (26-29) have the highest frequency in adopting the marginalization strategy. Though they are normally more experienced and mature, their work or businesses divide their attention from either culture. No correlation has been found between integration and each of the six factors, which suggests that there is no particularity for participants' integrating into the new culture. For immigrants, integration turns out to be an indispensable and realistic choice. Consequently, for the Guantou town immigrants, integration may be perceived as a desire to fit in rather than an attempt to socialize and communicate as much with the ethnic group as with the Americans. This finding corresponds to Barry's (2001) study of the East Asian immigrants in the United States. The intercultural contact factor of perceived discrimination predicts participants' preference for the rest three strategies. Affected by the feeling of being discriminated against, immigrants' reactions become various. They either tend to isolate from one or both of the ethnic culture and the host culture. 
Qualitative study together with quantitative study reveals the immigrants' acculturation patterns comprehensively. Immigrants' main acculturation difficulties lie in their understanding of America and China, identity, language, labor, outlook on life, attitudes towards money, and psychology. Immigrants believe it is easier to earn money in America than in China, which reflects their partial understanding both of the American culture and the Chinese culture. Their motivation of becoming an American citizen out of necessity may put them on the verge of identity crisis. Moreover, poor English proficiency frustrates their integrating eagerness. Apparently, driven by the ideal of 'Gold rush' in America, the immigrants' outlook on life is not that clear and specific for their future betterment. Their attitudes towards money seems to be problematic, for they become so consumed by money making that they are undergoing severe psychological and sociocultural changes in the acculturation process. Briefly, these difficulties lead to shape their acculturation patterns or acculturation dilemma that psychologically the general Guantou town immigrants have unconscious tendency to the integration strategy, while, for being conditioned by their acculturation difficulties, they in practice choose to separate.

\section{CONCLUSION}

The present study intends to find out the major acculturation strategies among the Guantou town immigrants in the American labor market and to probe into the factors that influence their preference. Furthermore, the acculturation difficulties and the distinctive acculturation patterns of the Guantou town immigrants are revealed by identifying their conceptions of the American Dream in a series of online interviews. The current study concludes with some practical suggestions to guide Chinese immigrants to acculturate smoothly in the new culture and to shed some light on the immigration consulting services in China.

Firstly, it is better for immigrants to have an accurate outlook on life. Secondly, before going abroad, an appropriate understanding of China and the new country ushers in the consciousness of differences either in economy, politics, society or culture between the two countries. Thirdly, immigrants need to be adequately equipped with the new culture's language, which is a mirror to the new culture; this is crucial in immigrants' acculturation. Fourthly, immigrants should be at ease in the face of setbacks like racial discrimination, identity crisis, or loneliness. Finally, it is advisable for them to improve themselves to a certain level so as to find a better job. Moreover, holding good attitudes towards money may keep them away from psychological pressures.

Further studies are expected, and there are some limitations identified throughout this survey. Firstly, the sample may not be typical enough to represent the overall Chinese immigrants in the American labor market. Secondly, the present research does not include longitudinal data. Lastly, the number of the participants involved is small.

\section{REFERENCES}

Asia Society. (2010). A Chronicle of the Chinese in America. Retrieved 2010, 3 October. http://asiasociety.org/countries-history/traditions/chronicle-chinese-america.

Barry, D. T. (2001). Development of a New Scale for Measuring Acculturation: The East Asian Acculturation Measure (EAAM). Journal of Immigrant Health, 3, (4), 38-55. 
Berry, J. W. (1980). “Acculturation as Varieties of Adaptation.” In A. M. Padilla (Ed.) Acculturation: Theory, Models, and Some New Findings, pp.9-25. Boulder, CO: Westview Press.

Berry, J. W. (1997). Immigration, Acculturation, and Adaptation. Applied Psychology: An International Review, 46, (1), 5-33.

Berry, J. W. (2003). “Conceptual Approaches to Acculturation.” In K. M. Chun, P. B. Organista, \& G. Marin (Ed.) Acculturation: Advances in Theory, Measurement, and Applied Research, pp.17-37. Washington, DC: American Psychological Association.

Berry, J. W., Phinney, J. S., Sam, D. L., \& Vedder, P. (2006). Immigrant Youth: Acculturation, Identity, and Adaptation. Applied Psychology: An International Review, 55, (3), 303-332.

Cullen, J. (2003). The American Dream: A Short History of an Idea that Shaped a Nation. New York: Oxford University Press.

Fan, Lei (2004). Acculturatation Strategies among Chinese Overseas Students in America. Huazhong University of Science and Technology.

Gordon, M. M. (1964). Assimilation in American Life. New York: Oxford University Press.

Graves, T. D. (1967). Psychological Acculturation in a Tri-ethnic Community. Southwestern Journal of Anthropology, 32, 337-350.

Kim, Y. Y. (2001). Becoming Intercultural: An Integrative Theory of Communication and Crosscultural Adaptation. Thousand Oaks, CA: Sage Publications.

Liang, S. Y. (2010). Asia, Faraway or Next Door? Retrieved 2010, 2 October. http://www.thechinabeat.org/?p=1865.

Ku, A. \& Aung, M. (2007). A Review of Acculturation and Ethnic Identity Research, The twelfth Cross-Cultural Research Conference, Honolulu, Hawaiian Islands.

Matsudaira, T. (2006). Measures of Psychological Acculturation: A Review. Transcult Psychiatry, 43, (3), 462-487.

Mendoza, R. H. (1984). “Acculturation and Sociocultural Variability.” In J. L. Martinez \& R. H. Mendoza (Ed.) Chicano Psychology, pp.61-75. Orlando, FL: Academic Press.

Owen, W. F. (1984). Interpretive Themes in Relational Communication. Quarterly Journal of Speech, 70, 271-287.

Redfield, R., Linton, R., \& Herskovits, M. (1936). Memorandum on the Study of Acculturation. American Anthropologist, 38, 149-152. 
Rudmin, F. W. (2003). Critical History of the Acculturation Psychology of Assimilation, Separation, Integration, and Marginalization. Review of General Psychology, 7, 3-37.

Ruhm, C. J. (1997). Is High School Employment Consumption or Investment? Journal of Labor Economics, 15, (4), 735-776.

Sorensen, E., Bean, F. D., Ku, L., \& Zimmerman, W. (1992). Immigrant Categories and the U.S. Job Market: Do They Make a Difference? Washington, DC: The Urban Institute.

Suinn, R. M., Rickard-Figueroa, K., Lew, S., \& Vigil, P. (1987). The Suinn-Lew Asian Selfidentity Acculturation Scale: An Initial Report. Educational and Psychological Measurement, 47,401-407.

Tian, G. (1999). Canadian Chinese, Chinese Canadian: Coping and Adapting in North America. Lewiston, NY: The Edwin Mellen Press.

Van de Vijver, F. J. R., \& Leung, K. (1997). Methods and Data Analysis for Cross-cultural Research. Newbury Park, CA: Sage.

Ward, C., \& Kennedy, A. (1999). The Measurement of Sociocultural Adaptation. International Journal of Intercultural Relations, 23, 659-677.

Ward, C., Bochner, S., \& Furnham, A. (2001). The Psychology of Culture Shock. New York, NY: Routledge. 